ISSN : 2252-3839 (Print)

ISSN : 2549-2403 (On Line)

DOI : 10.28989/compiler.v9i1.650

http://ejournals.stta.ac.id/index.php/compiler/

\title{
RIGID BODY IN THE THREE DIMENSIONAL RIGGING MODEL FOR CAR ANIMATION IN A BUMPY ROAD
}

\author{
Salam Aryanto \\ Teknik Informatika Sekolah Tinggi Teknologi Adisutjipto Yogyakarta \\ J1. Janti Blok-R Lanud Adisutjipto Yogyakarta \\ Email : salamaryanto@stta.ac.id
}

\begin{abstract}
The development of animation technology is currently very rapid, but to animate a three-dimensional object beforehand must be done by preparing the framework manually. Also in the real world, when two objects collide, they do not penetrate each other. When a collision occurs, the interaction force will change the original state of two objects, such as position, trajectory, and direction. The purpose of this study focuses on the rigid body in a three dimensional rigging model arrangement for car animation scenarios on a bumpy road. This approach focuses on reducing manual movement by animators when animating threedimensional car models. The result is to make a car animation on a bumpy road well, then the arrangement of the framework on the car has a mass $=1946 \mathrm{~kg}$ and gravity $=-981.001$ $\mathrm{cm} / \mathrm{s}^{2}$. As well as knowing the results of the animated motion of the car on a bumpy road with a tolerance of distance between the car's wheels and the trajectory of $4.44 \mathrm{~cm}$ without applying a rigid body to the arrangement of the car's frame. While the motion animation of the car on a bumpy road with good results where the tolerance of the distance between the car wheels and the track is $0.045 \mathrm{~cm}$ after applying a rigid body to the arrangement of the car's frame.
\end{abstract}

Keywords: rigid body, arrangement, rigging, animation, vehicle

\section{Latar Belakang Masalah}

Pada animasi digital hampir seluruh proses produksi dikerjakan menggunakan perangkat komputer, seperti membuat model, memberikan material, penyusunan kerangka gerak, menganimasikan objek, dan lain lain. Namun untuk menganimasikan sebuah objek tiga dimensi sebelumnya harus dilakukan penyusunan kerangka secara manual untuk menentukan struktur internalnya dan untuk menentukan hasil gerakan objek yang dianimasikan. Di dunia nyata, ketika dua benda bertabrakan, mereka bertumbukan, namun keduanya tidak saling menembus. Ketika tumbukan terjadi, gaya interaksi akan mengubah keadaan semula dari dua benda, seperti posisi, lintasan, dan arah. Oleh karena itu, dalam simulasi animasi, jika tumbukan antar objek terjadi, keadaan gerakan asli sebuah objek akan berubah karena kekuatan interaksi [1].

Berdasarkan uraian diatas peneliti akan melakukan eksperimen dengan skenario percobaan terhadap proses penyusunan kerangka pada model mobil tiga dimensi untuk menimbulkan tumbukan, gaya, dan massa pada model mobil sehingga menghasilkan animasi yang baik dengan memanfaatkan rigid body. Karena dari hasil pengujian dengan gaya gravitasi, ada simulasi suspensi di mobil. Melalui simulasi mobil dan lingkungan sekitarnya dari berbagai parameter yang ditetapkan, dapat dilakukan berbagai gerakan animasi berbasis simulasi fisika [1].

Oleh karena itu, penelitian ini berfokus pada rigid body di dalam susunan kerangka model tiga dimensi untuk skenario animasi mobil di jalan bergelombang. Pendekatan ini berfokus untuk mengurangi pergerakan secara manual oleh animator pada saat menganimasikan model mobil tiga dimensi. Secara khusus penyusunan kerangka dengan 
mengimplementasikan rigid body pada model mobil tiga dimensi bertujuan untuk menciptakan simulasi fisika sehingga gerakan animasi mobil tiga dimensi lebih dinamis.

\section{Metodologi Penelitian}

Metode penelitian yang penulis gunakan adalah eksperimental. metode eksperimen adalah prosedur penelitian yang dilakukan untuk mengungkapkan hubungan sebab akibat dua variabel atau lebih, dengan mengendalikan pengaruh variabel yang lain. Metode ini dilaksanakan dengan memberikan variabel bebas secara sengaja (bersifat induse) kepada objek penelitian untuk diketahui akibatnya di dalam variabel terikat [2].

Terdapat tiga prinsip dasar yang terdapat dalam desain eksperimen ini, antara lain sebagai berikut:

1.) Replication, yang merupakan pengulangan dari metode penyusunan kerangka dasar pada model kendaraan tiga dimensi tanpa menerapkan rigid body.

2.) Randomization, prinsip ini digunakan pada pengujian hasil penyusunan tulang yang sudah diberikan rigid body dengan beberapa skenario percobaan. Pengujian ini valid bila pengamatan didistribusikan secara bebas yang dilakukan dengan pengambilan sampel secara random atau acak.

3.) Blocking, merupakan prinsip yang digunakan untuk mengisolasi hasil yang sudah baik dan sesuai dengan indikator yang ada dari pengaruh faktor lain supaya hasil eksperimen menjadi lebih akurat.

Rigid body dapat disimulasikan secara dinamis berkaitan dengan kontak dan tumbukan, serta badan yang dikendalikan secara dinamis merespon gerakan sendi dan tumbukan dengan benda lain. Objek rigid body dapat berinteraksi dengan lingkungan melalui kontak fisik. selain itu juga menunjukkan bahwa gaya (selain gaya gravitasi) dapat bekerja pada objek selama fase kontak fisik [3].

Rigid body merupakan sebuah sifat material (padat, kaku, keras) dalam tiga dimensi. Rigid body yang ideal memiliki aturan yang jelas dan terdefinisi dengan baik untuk bagaimana sebuah objek bergerak di bawah aksi kekuatan dan momen, serta bagaimana batasan ideal seperti bergulir dengan sempurna, bergeser, dalam sistem pergerakan sebuah objek. Dalam hukum tumbukan inkremental, percepatan gaya rigid body dan persamaan keseimbangan momentum digunakan untuk menggambarkan dinamika selama tumbukan [4]. 


\subsection{Prinsip Kerja Sistem}

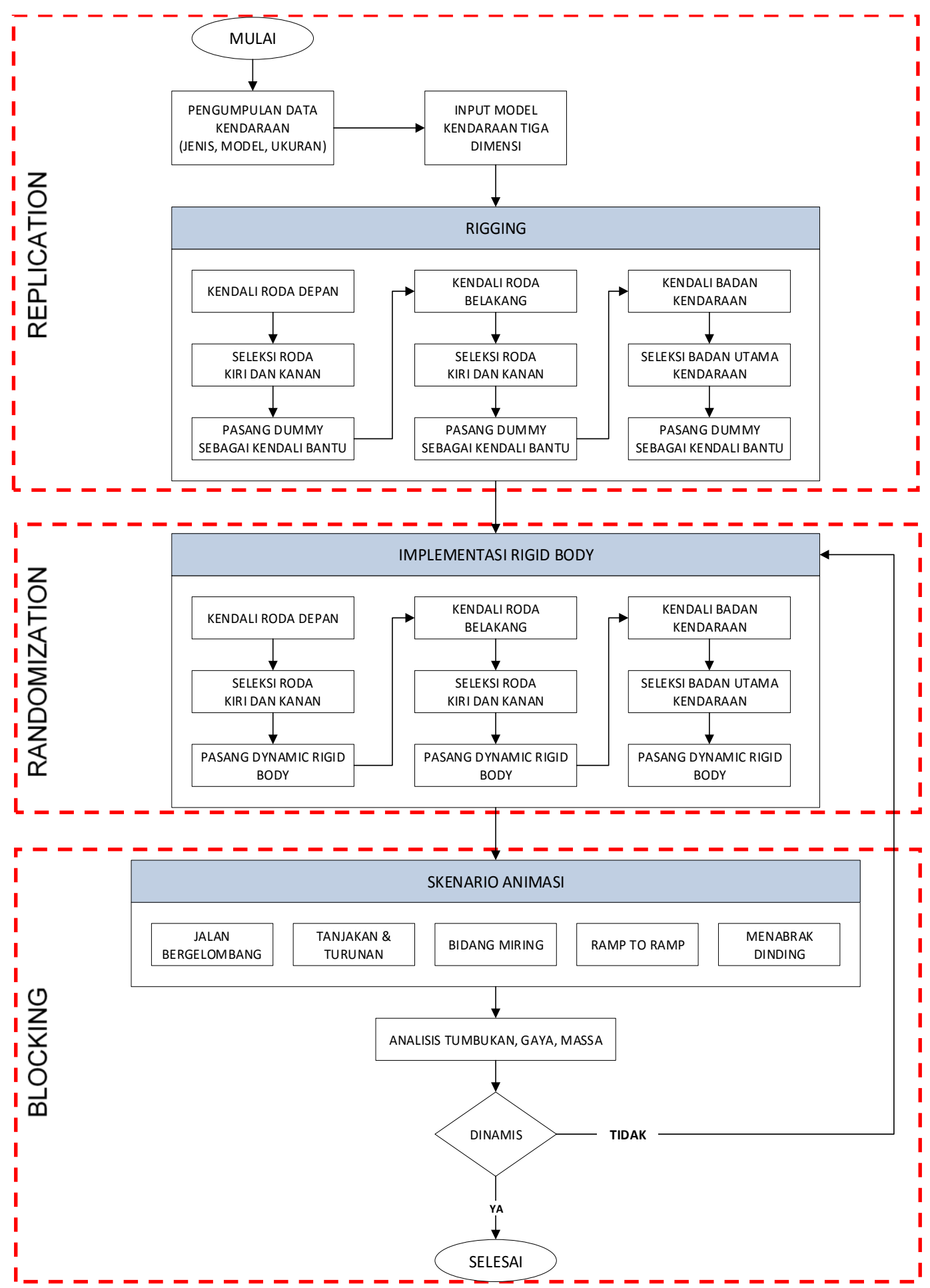

Gambar 1. Alur Penelitian

Alur penelitian pada gambar 1 dimulai dari tahapan pertama dalam mengumpulkan data yang dilakukan dengan studi dari video, website, buku, jurnal nasional dan internasional. Data yang digunakan adalah model mobil tiga dimensi Toyota FJ Cruiser 2007. Model mobil tiga dimensi tersebut disesuaikan dengan data jenis, model, dan ukuran mobil yang sebenarnya. 
Tahap selanjutnya adalah replication dimana dilakukan proses penyusunan kerangka model mobil tiga dimensi. Pada tahap ini dilakukan pemasangan kerangka dan kendali untuk menggerakkan model mobil. Kendali dipasang pada bagian-bagian kendali utama model mobil, seperti pada roda depan, roda belakang, dan badan mobil. Semua kerangka dan kendali tersebut dihubungkan agar saling berkaitan fungsinya pada saat dianimasikan. Hal ini dilakukan untuk memudahkan dalam mengendalikan gerakan model mobil saat menjalankan skenario percobaan.

Pada tahap randomization dilakukan implementasi rigid body, yang pertama dilakukan adalah menentukan bagian-bagian model mobil yang bertumbukan langsung dengan lingkungan saat dilakukan uji coba. Bagian-bagian tersebut meliputi roda depan, roda belakang, dan badan mobil. Dimana roda depan dan belakang bertumbukan langsung dengan permukaan landasan tempat model mobil berjalan. Selanjutnya badan model mobil bertumbukan dengan dinding saat proses uji coba.

Untuk blocking dilakukan analisis terhadap gerakan animasi dinamis model mobil tiga dimensi dilakukan beberapa skenario percobaan. Skenario tersebut dipilih berdasarkan penelitian tentang simulasi mobil dinamis [5].

\section{Hasil dan Pembahasan}

\subsection{Penyusunan Kerangka Kendali Roda Depan}

Tahap selanjutnya adalah pemasangan kerangka kendali atau yang biasa disebut dengan istilah penyusunan kerangka. Diawali dengan membuat kerangka kendali pada bagian roda depan kanan, roda depan kiri, roda belakang kanan, dan roda belakang bagian kiri. Karena dari setiap skenario percobaan pada rigging terhadap model kendaraan tiga dimensi memberikan hasil gerakan animasi yang dinamis pada model kendaraan untuk setiap skenario lingkungan yang berbeda. Adapun perubahan koordinat pada kurva, menunjukkan perubahan pada sumbu $\mathrm{Z}$ sesuai dengan bentuk jalan yang dilalui model kendaraan [6]. Untuk kerangka kendali berikutnya dibuat penghubung antara roda kanan dan roda kiri yaitu poros depan dan poros bagian belakang. Kedua poros ini juga harus diberi penghubung, dalam hal ini penulis memberi nama rig center. Langkah terakhir membuat kerangka kendali untuk bagian badan mobil. Pada gambar 2 ditunjukkan kotak berwarna biru.
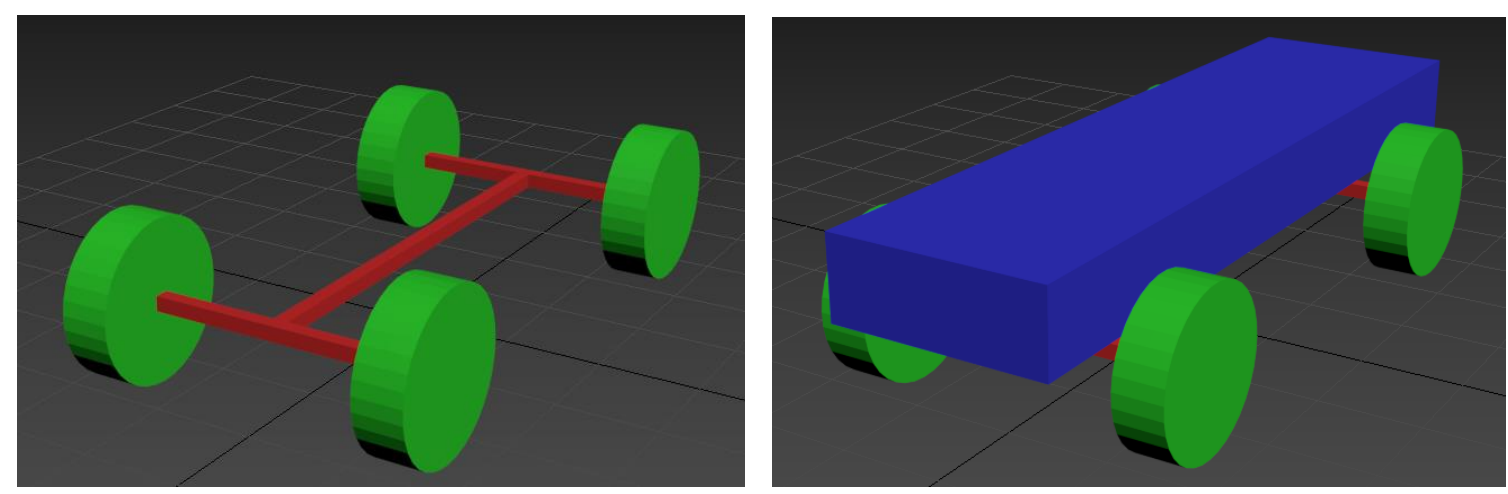

Gambar 2. Model Susunan Kerangka Mobil 
Setelah semua persiapan kerangka kendali selesai dibuat, maka selanjutnya adalah menggabungkan kerangka kendali tersebut dengan model mobil tiga dimensi agar setiap bagian mobil seperti roda dan badan mobil dapat digerakkan. Hasil pengujian simulasi menunjukkan bahwa device steering wheel dapat menghasilkan output yang sesuai dengan kontrol kemudi pada mobil [7].
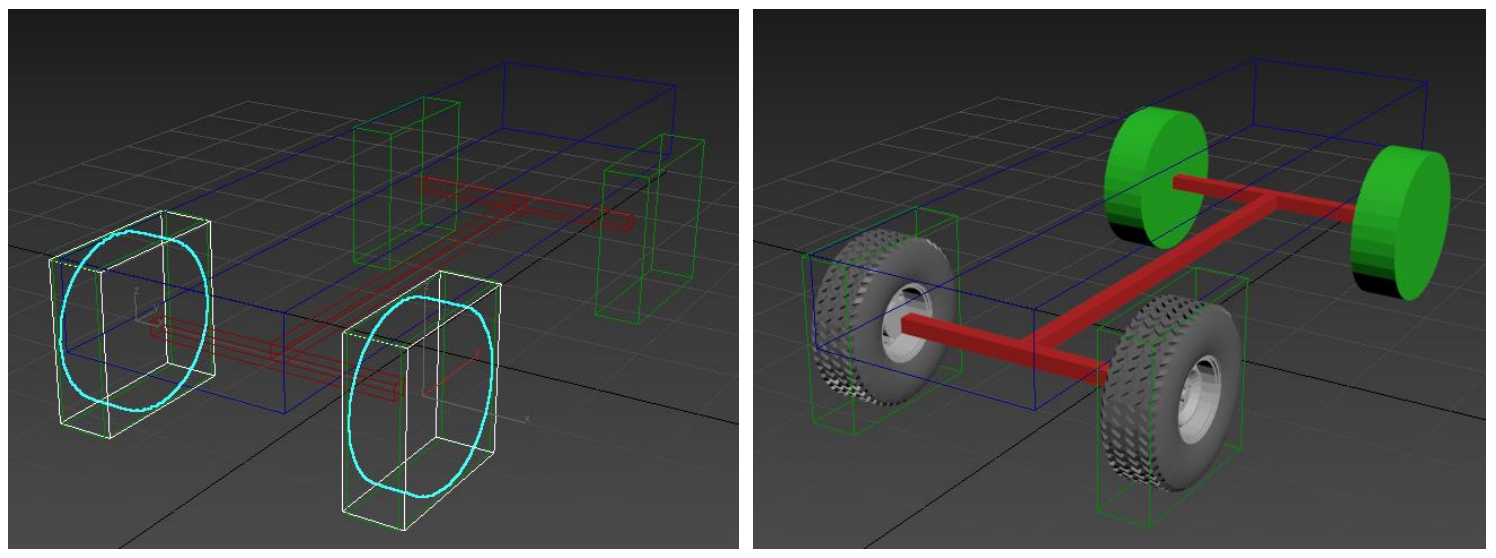

Gambar 3. Penyusunan kerangka Roda Depan

Gambar 3 di atas menunjukkan proses pemasangan kerangka kendali roda depan bagian kanan dan kiri. Pada gambar tersebut posisi kendali roda tepat berada di tengah model roda mobil. Hal tersebut bertujuan agar model roda dapat berputar pada porosnya.

\subsection{Penyusunan kerangka Kendali Roda Belakang}
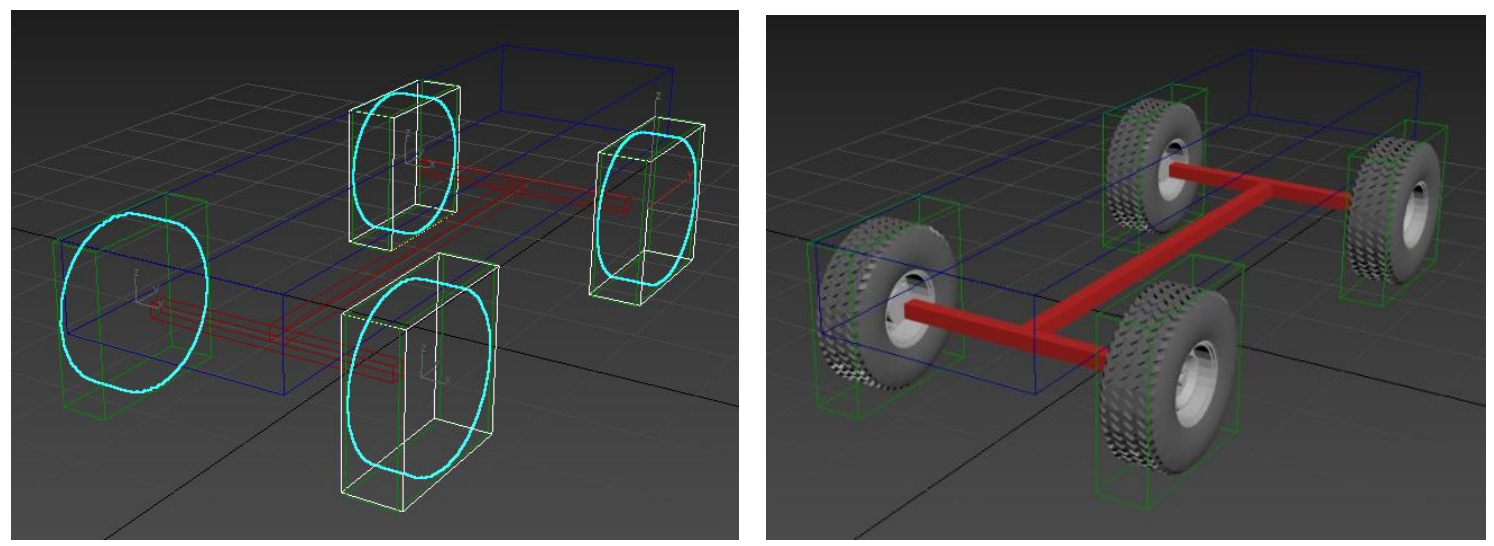

Gambar 4. Penyusunan kerangka Roda Belakang

Gambar 4 di atas juga menunjukkan proses pemasangan kerangka kendali. Namun kali ini dipasang pada roda belakang bagian kanan dan kiri. Pada gambar tersebut posisi kendali roda tepat berada di tengah model roda mobil. Hal tersebut bertujuan agar model roda dapat berputar pada porosnya seperti pada roda bagian depan. 


\subsection{Penyusunan kerangka Kendali Badan Mobil}
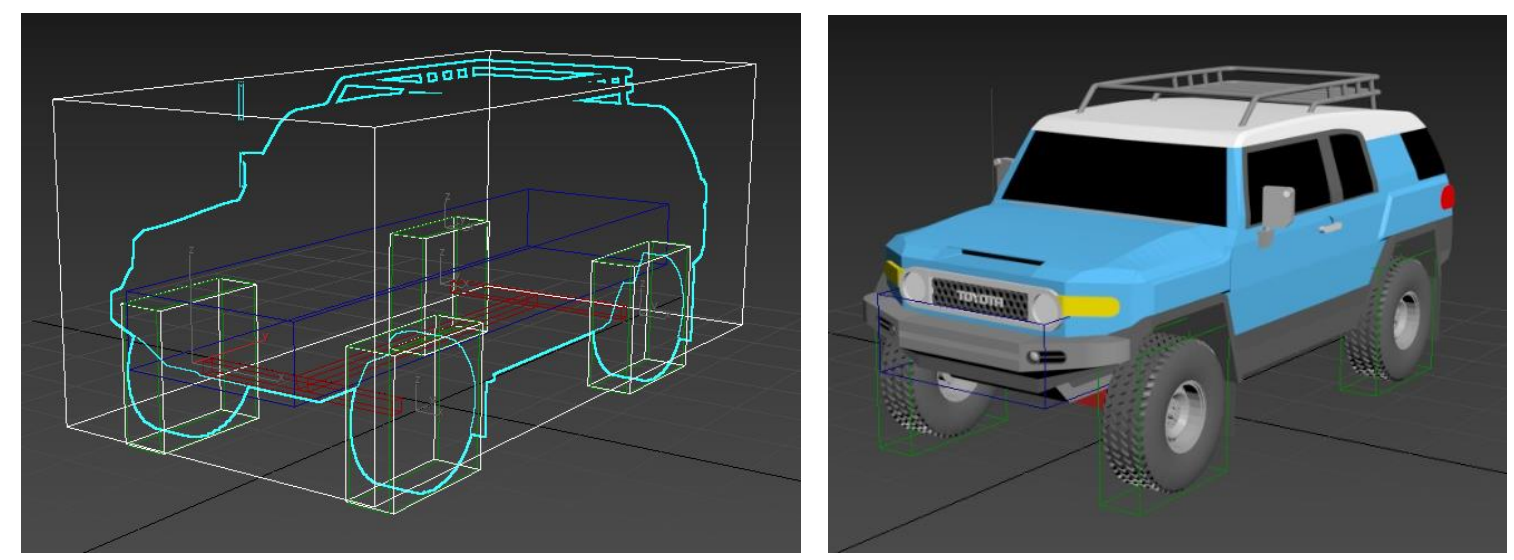

Gambar 5. Penyusunan kerangka Badan Mobil

Gambar 5 merupakan pemasangan kerangka kendali yang terakhir yaitu pada model badan mobil. Badan mobil dipasang pada kotak berwarna biru yang sebelumnya sudah dibahas pada proses pembuatan kerangka kendali. Hal ini dilakukan agar posisi badan mobil selalu berada diaatas roda. Artinya badan mobil tidak menempel ataupun berada diantara roda-roda. Pemodelan yang digunakan pada penelitian ini masih menggunakan rigid body model, karena analisisnya hanya untuk gaya kontak/ impak saja [8].

\subsection{Skenario Jalan Bergelombang}

Berikut gambar 6 yang menunjukkan hasil keseluruhan dari setiap proses penyusunan kerangka dan implementasi rigid body. Pada gambar tersebut terlihat jelas keseluruhan bagian serta daftar bagian-bagian model, bagian penyusunan kerangka, dan bagian dari implementasi rigid body yang menempel pada model mobil.

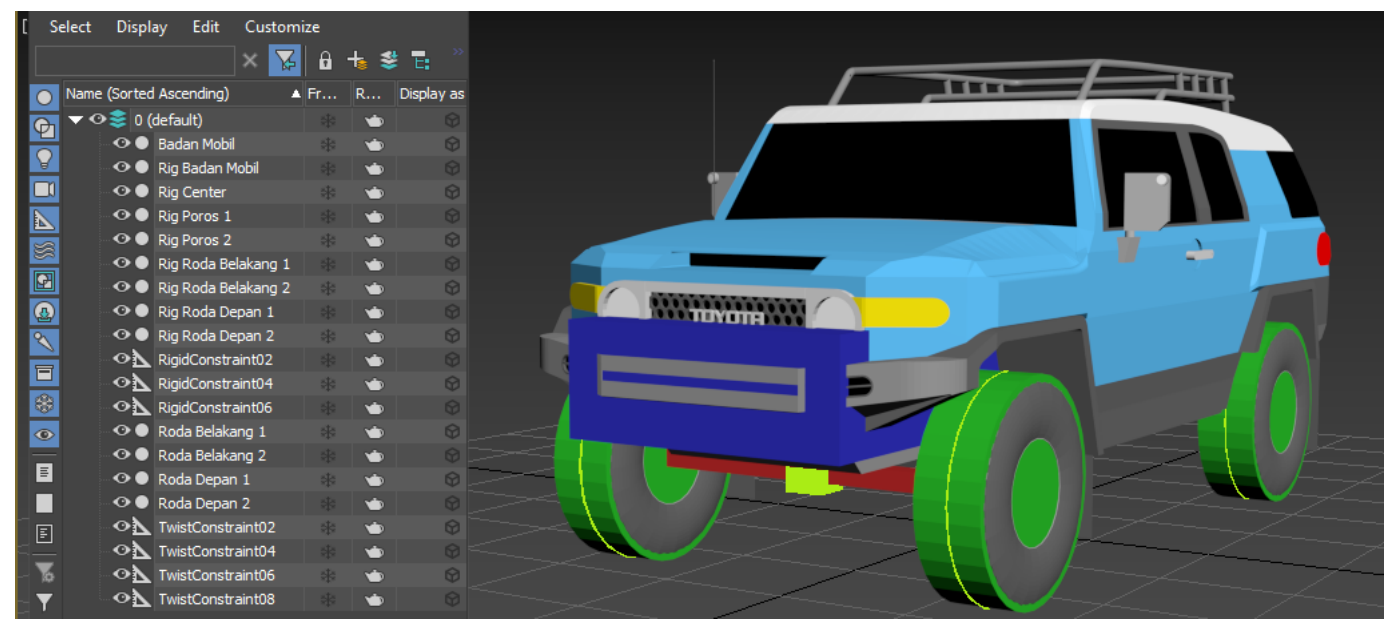

Gambar 6. Implementasi Rigid Body Model Mobil

Untuk menghasilkan jarak tumbukan antara lintasan dengan model mobil yang baik maka dilakukan eksperimen dengan merubah parameter dari solver iteration, ditunjukkan pada gambar 7. Dimana parameter ini merupakan pengaturan toleransi jarak tumbukan yang 
terjadi diatara dua buah objek rigid. Angka yang semakin besar akan sangat berguna pada objek dengan rangkaian yang saling terhubung.
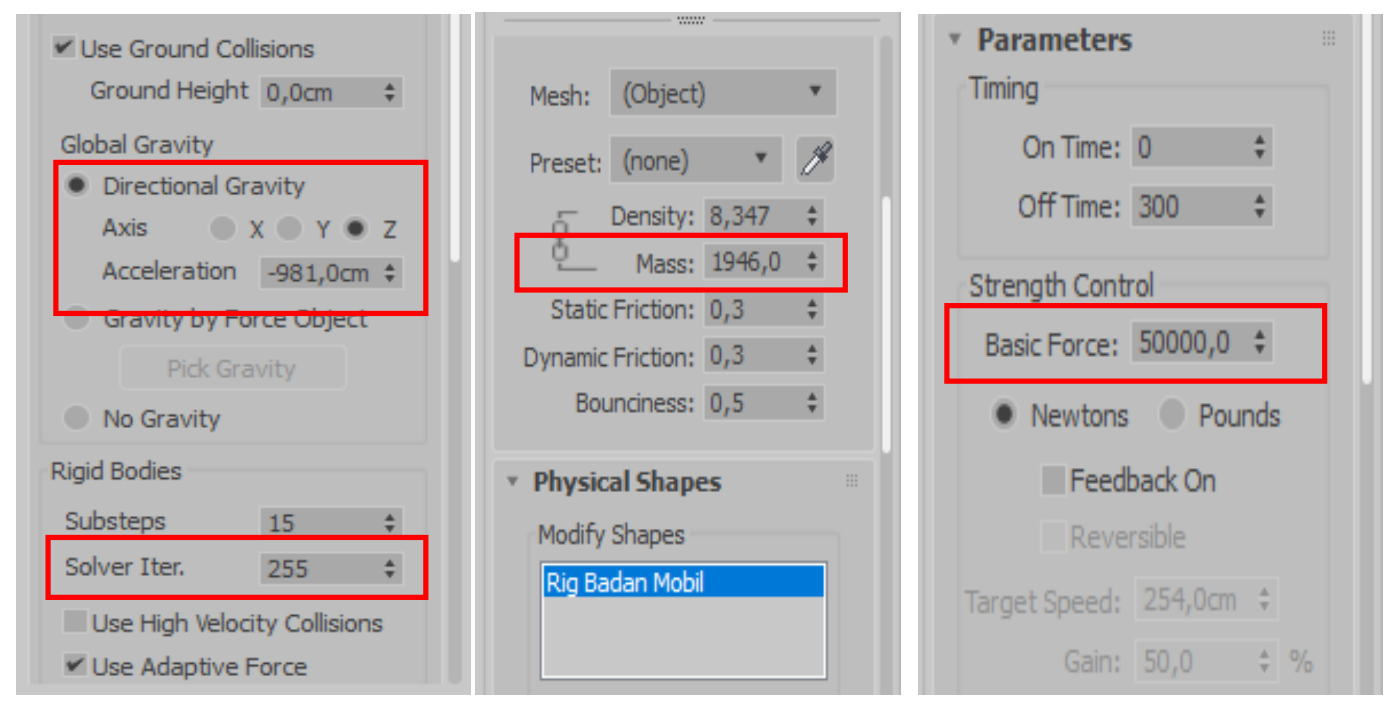

Gambar 7. Parameter Gravitasi, Massa, dan Toleransi Tumbukan

Berikut gambar 8 yang menunjukkan posisi pada pandangan perspektif model mobil pada skenario percobaan model mobil berjalan pada jalan bergelombang. Dalam merancang sistem kontrol, dibutuhkan pemodelan dari plant yang akan dikontrol, pada penelitian tentang simulasi pesawat yang dilakukan oleh Fahmi Rezza Djuliandri, Aris Triwiyatno, and Budi Setiyono menggunakan fixed wing [9]. Sementara untuk kendali dan gerakan mobil pada simulasi ini menggunakan beberapa parameter untuk percobaan ini yaitu massa $=1946 \mathrm{~kg}$, gaya gravitasi $=-981.001 \mathrm{~cm} / \mathrm{s}^{2}$, gaya dorong $=50.000$ Newton .

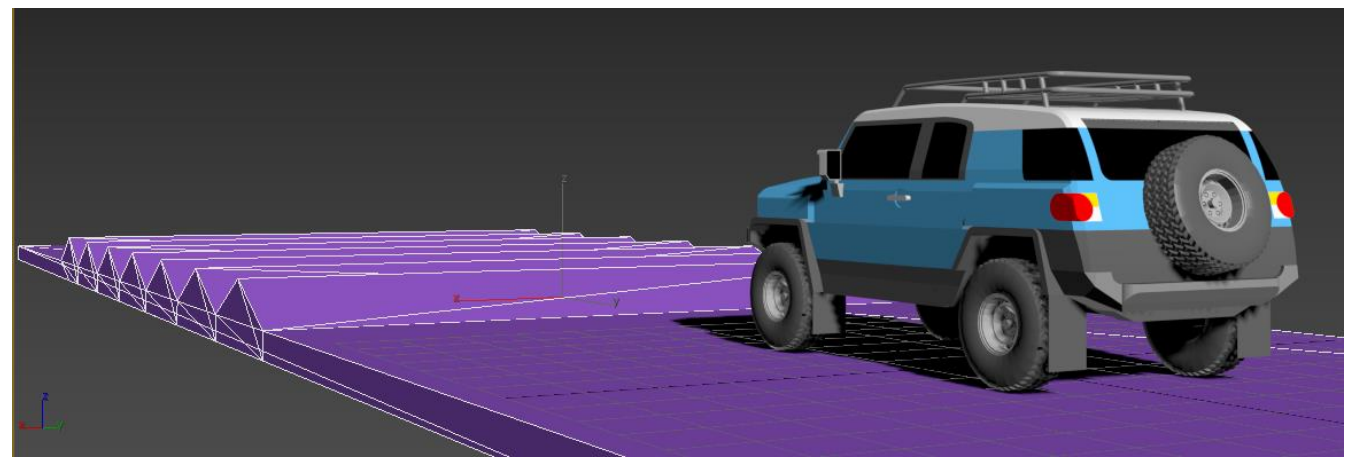

Gambar 8. Perspektif Skenario Jalan Bergelombang

Pada gambar 9 menunjukkan model mobil bergerak dan pada frame ke 60 dan kurva menunjukan perubahan pada posisi sumbu $\mathrm{Z}$ ke arah atas. Artinya perubahan tersebut terjadi karena adanya tumbukan pada frame ke 60, sehingga model mobil bergerak melewati jalan yang bergelombang tersebut sesuai dengan kontur jalan tersebut. 


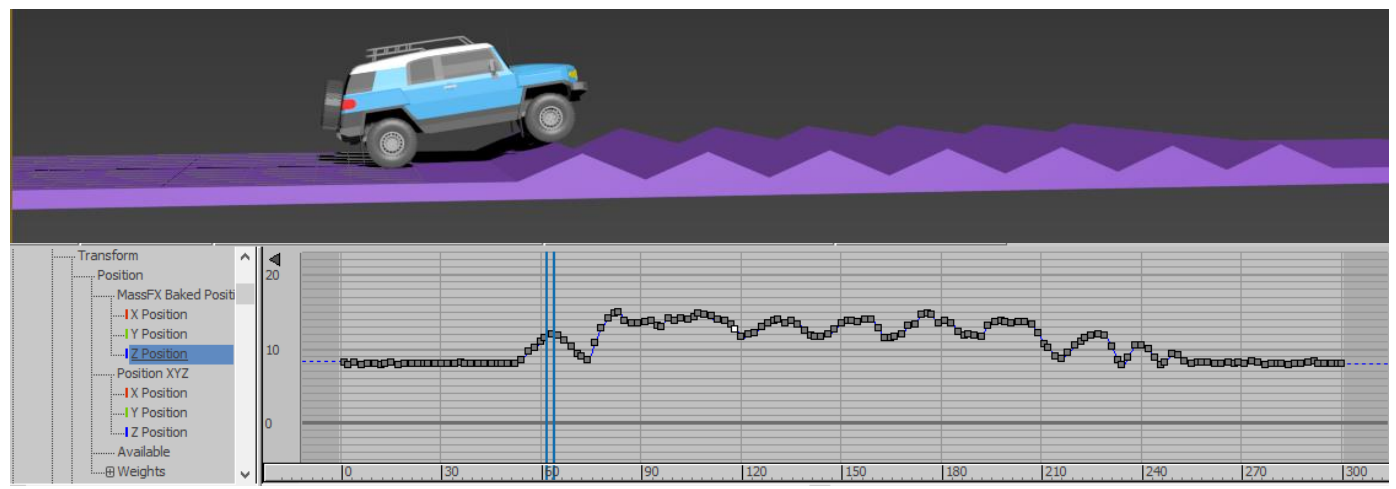

Gambar 9. Skenario Jalan Bergelombang frame 60

Pada gambar 10 menunjukkan model mobil bergerak dan pada frame ke 75 dan kurva menunjukan perubahan pada posisi sumbu $\mathrm{Z}$ ke arah bawah. Artinya perubahan tersebut terjadi karena adanya tumbukan pada frame ke 75, sehingga model mobil bergerak melewati jalan yang bergelombang tersebut sesuai dengan kontur jalan tersebut.

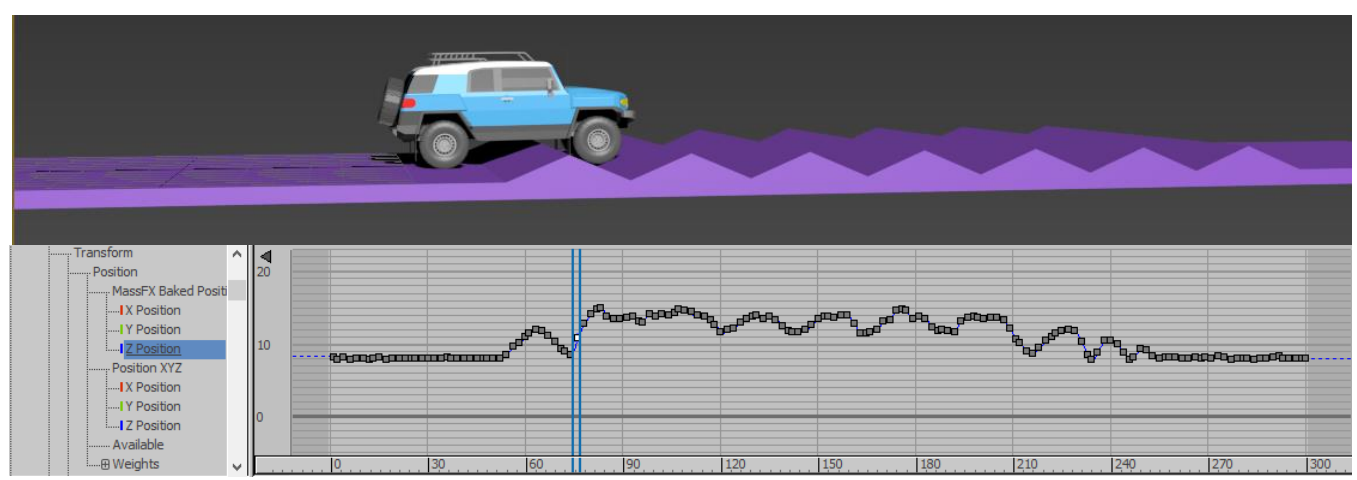

Gambar 10. Skenario Jalan Bergelombang frame 75

Pada gambar 11 menunjukkan model mobil bergerak dan pada frame ke 85 dan kurva menunjukan perubahan pada posisi sumbu $\mathrm{Z}$ ke arah atas. Artinya perubahan tersebut terjadi karena adanya tumbukan pada frame ke 85, sehingga model mobil bergerak melayang melewati jalan yang bergelombang tersebut sesuai dengan kontur jalan tersebut.

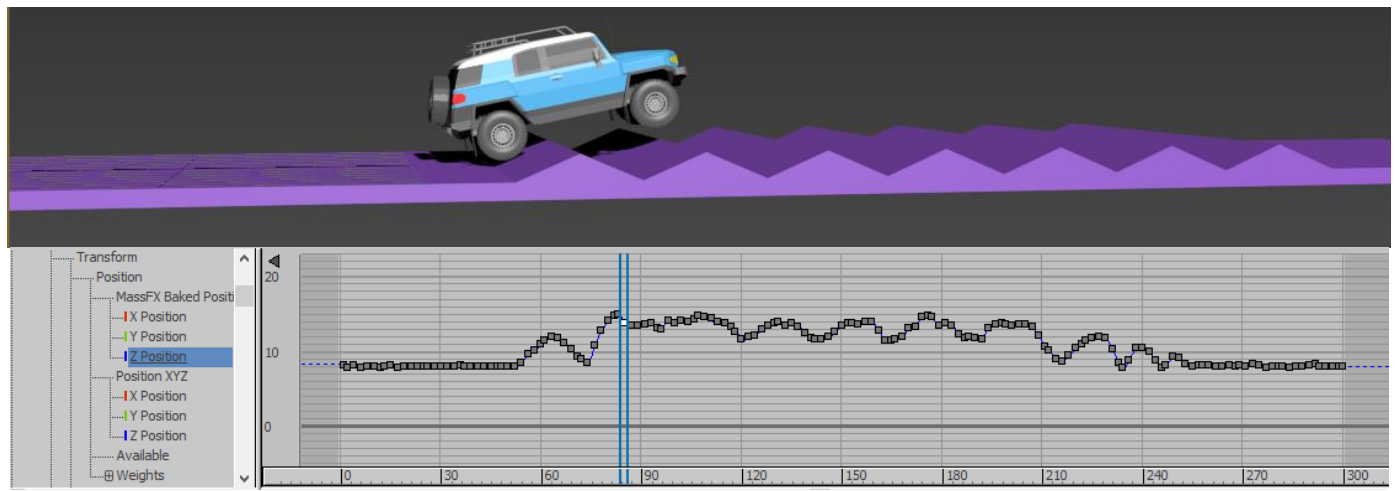

Gambar 11. Skenario Jalan Bergelombang frame 85

Pada gambar 12 menunjukkan model mobil bergerak dan pada frame ke 100 dan kurva menunjukan perubahan pada posisi sumbu $\mathrm{Z}$ ke arah bawah. Artinya perubahan tersebut terjadi karena adanya tumbukan pada frame ke 100, sehingga model mobil bergerak melewati jalan yang bergelombang tersebut sesuai dengan kontur jalan tersebut. 


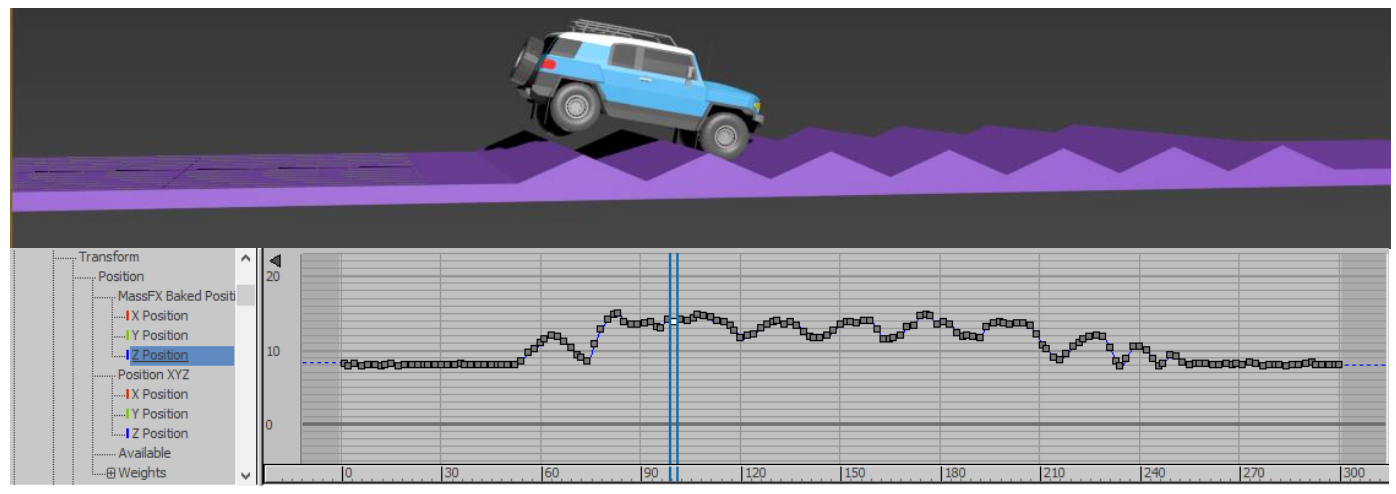

Gambar 12. Skenario Jalan Bergelombang frame 100

Pada gambar 13 menunjukkan model mobil bergerak dan pada frame ke 105 dan kurva menunjukan perubahan pada posisi sumbu $\mathrm{Z}$ ke arah atas. Artinya perubahan tersebut terjadi karena adanya tumbukan pada frame ke 105, sehingga model mobil bergerak melewati jalan yang bergelombang tersebut sesuai dengan kontur jalan tersebut.

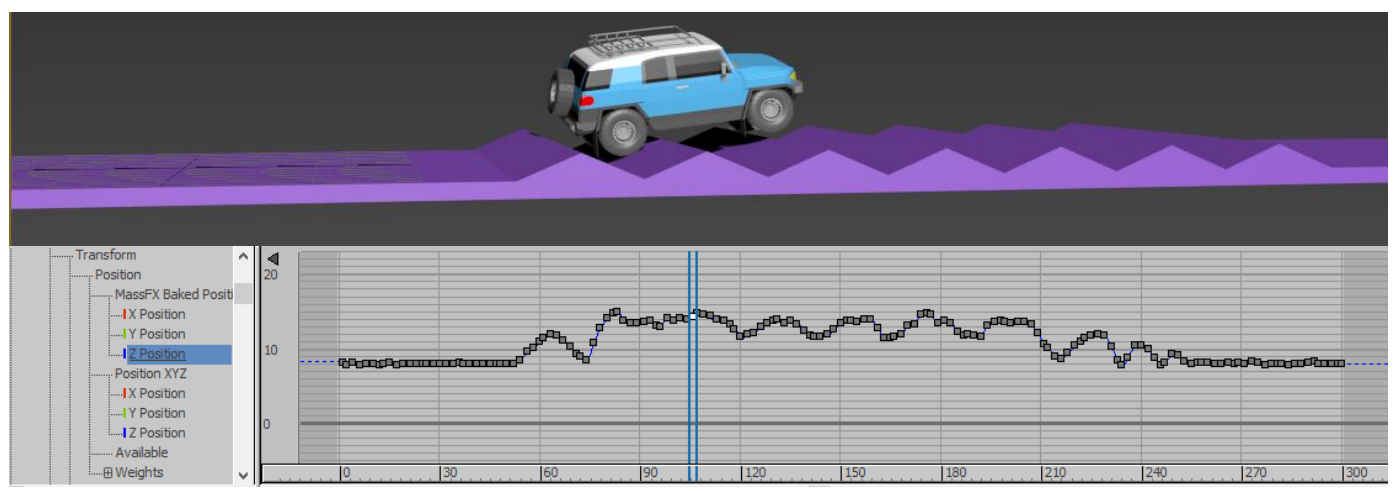

Gambar 13. Skenario Jalan Bergelombang frame 105

Tabel 1. Sebelum Implementasi Rigid Body

\begin{tabular}{|c|c|c|c|}
\hline Key Frame & $\begin{array}{l}\text { Koordinat } \\
\text { Lintasan }\end{array}$ & Koordinat Mobil & Selisih \\
\hline Frame 30 & $8 \mathrm{~cm}$ & $8 \mathrm{~cm}$ & $0 \mathrm{~cm}$ \\
\hline Frame 60 & $12 \mathrm{~cm}$ & $8 \mathrm{~cm}$ & $4 \mathrm{~cm}$ \\
\hline Frame 90 & $14 \mathrm{~cm}$ & $8 \mathrm{~cm}$ & $8 \mathrm{~cm}$ \\
\hline Frame 120 & $12 \mathrm{~cm}$ & $8 \mathrm{~cm}$ & $4 \mathrm{~cm}$ \\
\hline Frame 150 & $14 \mathrm{~cm}$ & $8 \mathrm{~cm}$ & $8 \mathrm{~cm}$ \\
\hline Frame 180 & $14 \mathrm{~cm}$ & $8 \mathrm{~cm}$ & $8 \mathrm{~cm}$ \\
\hline Frame 210 & $12 \mathrm{~cm}$ & $8 \mathrm{~cm}$ & $4 \mathrm{~cm}$ \\
\hline Frame 240 & $12 \mathrm{~cm}$ & $8 \mathrm{~cm}$ & $4 \mathrm{~cm}$ \\
\hline Frame 270 & $8 \mathrm{~cm}$ & $8 \mathrm{~cm}$ & $0 \mathrm{~cm}$ \\
\hline & & Rata - rata & $4,44 \mathrm{~cm}$ \\
\hline
\end{tabular}

Pada tabel 1 menunjukkan hasil untuk setiap frame gerakan animasi pada model mobil tiga dimensi belum terjadi tumbukan sama sekali. Dimana dalam tabel tersebut belum ada implementasi rigid body pada model mobil. Hal tersebut ditunjukkan pada koordinat mobil yang tidak berubah mengikuti koordinat lintasan. Artinya model mobil hanya bergerak lurus menembus objek lintasan yang dilalui. 
Pada gambar 14 ditunjukkan hasil perbandingan grafik untuk setiap frame gerakan animasi pada model mobil tiga dimensi belum terjadi tumbukan sama sekali. Dimana dalam tabel tersebut belum ada implementasi rigid body pada model mobil. Sedangkan gambar 15 menunjukkan hasil grafik untuk setiap frame gerakan animasi pada model mobil tiga dimensi sudah terjadi tumbukan. Dimana dalam tabel tersebut sudah ada implementasi rigid body pada model mobil. Hal tersebut ditunjukkan pada grafik koordinat mobil yang berubah mengikuti koordinat lintasan. Artinya model mobil tidak hanya bergerak lurus menembus objek lintasan yang dilalui namun dapat bergerak mengikuti koordinat dan bentuk lintasan.

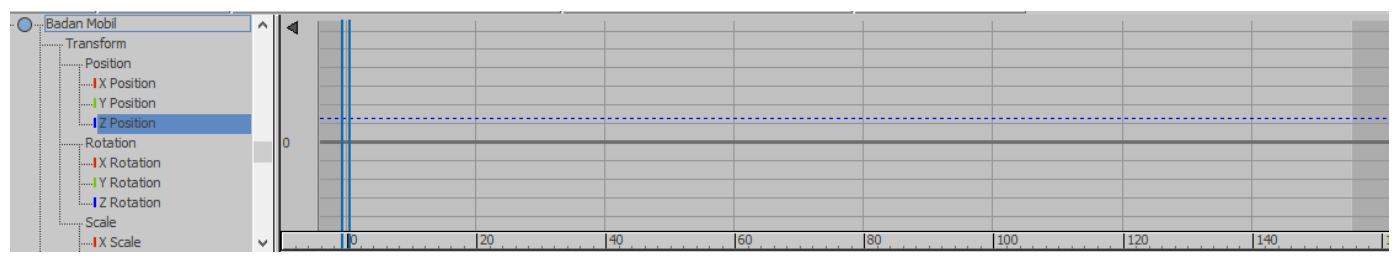

Gambar 14. Grafik Sebelum Implementasi Rigid Body

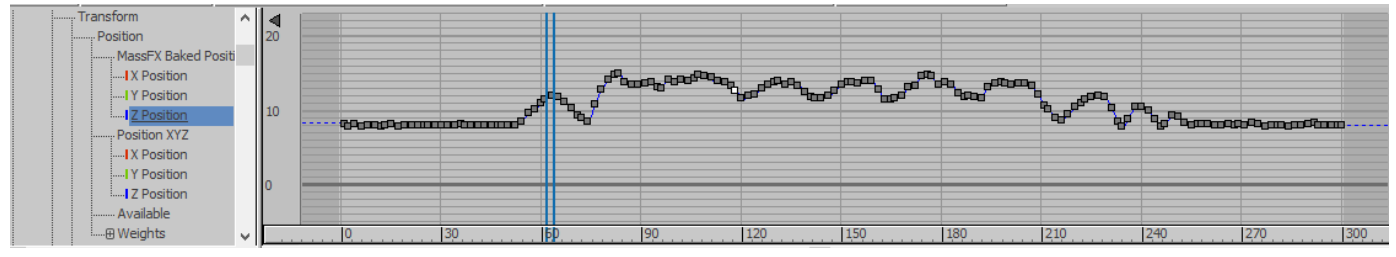

Gambar 15. Grafik Sesudah Implementasi Rigid Body

Tabel 2. Sesudah Implementasi Rigid Body

\begin{tabular}{|c|c|c|c|}
\hline Key Frame & $\begin{array}{c}\text { Koordinat } \\
\text { Lintasan }\end{array}$ & Koordinat Mobil & Selisish \\
\hline Frame 30 & $8 \mathrm{~cm}$ & $7,995 \mathrm{~cm}$ & $0,005 \mathrm{~cm}$ \\
\hline Frame 60 & $12 \mathrm{~cm}$ & $11,833 \mathrm{~cm}$ & $0,167 \mathrm{~cm}$ \\
\hline Frame 90 & $14 \mathrm{~cm}$ & $13,626 \mathrm{~cm}$ & $0,374 \mathrm{~cm}$ \\
\hline Frame 120 & $12 \mathrm{~cm}$ & $11,693 \mathrm{~cm}$ & $0,307 \mathrm{~cm}$ \\
\hline Frame 150 & $14 \mathrm{~cm}$ & $13,672 \mathrm{~cm}$ & $0,328 \mathrm{~cm}$ \\
\hline Frame 180 & $14 \mathrm{~cm}$ & $13,796 \mathrm{~cm}$ & $0,204 \mathrm{~cm}$ \\
\hline Frame 210 & $12 \mathrm{~cm}$ & $11,353 \mathrm{~cm}$ & $0,647 \mathrm{~cm}$ \\
\hline Frame 240 & $12 \mathrm{~cm}$ & $10,488 \mathrm{~cm}$ & $1,512 \mathrm{~cm}$ \\
\hline Frame 270 & $8 \mathrm{~cm}$ & $7,900 \mathrm{~cm}$ & $0,100 \mathrm{~cm}$ \\
\hline \multicolumn{2}{|c}{} & Rata $-\mathrm{rata}$ & $0,405 \mathrm{~cm}$ \\
\hline
\end{tabular}

Pada tabel 2 menunjukkan hasil untuk setiap frame gerakan animasi pada model mobil tiga dimensi sudah terjadi tumbukan. Dimana dalam tabel tersebut sudah ada implementasi rigid body pada model mobil. Hal tersebut ditunjukkan pada koordinat mobil yang berubah mengikuti koordinat lintasan. Artinya model mobil tidak hanya bergerak lurus menembus objek lintasan yang dilalui namun dapat bergerak mengikuti koordinat dan bentuk lintasan. Untuk hasil koordinat mobil yang ditunjukkan dalam tabel tidak sama persis dengan angka yang ditunjukkan pada koordinat lintasan. Hal ini disebabkan adanya gerakan naik turun dari suspensi yang bekerja pada model mobil tiga dimensi. 
Tabel .3 Perbandingan Rata - Rata Jarak Tumbukan Lintasan dengan Kendaraan

\begin{tabular}{|c|c|c|}
\hline \multirow{2}{*}{ Skenario } & \multicolumn{2}{|c|}{ Rata - Rata Jarak Lintasan dengan Kendaraan } \\
\cline { 2 - 3 } & $\begin{array}{c}\text { Sebelum Implementasi } \\
\text { Rigid Body }\end{array}$ & $\begin{array}{c}\text { Sesudah Implementasi } \\
\text { Rigid Body }\end{array}$ \\
\hline Jalan Bergelombang & $4,44 \mathrm{~cm}$ & $0,405 \mathrm{~cm}$ \\
\hline
\end{tabular}

Pada tabel 3 dapat dilihat bahwa pada skenario jalan bergelombang memiliki jarak lintasan dengan kendaraan sebelum implementasi rigid body menghasilkan nilai yang sangat besar dikarenakan tidak ada tumbukan sama sekali sedangkan sesudah implementasi rigid body menghasilkan nilai yang kecil untuk jarak antara lintasan dengan model kendaraan.

\section{Kesimpulan}

Berdasarkan hasil penelitian dan percobaan, maka dapat disimpulkan beberapa hal mengenai rigid body pada susunan kerangka model tiga dimensi untuk animasi mobil di jalan bergelombang.

1. Untuk menghasilkan animasi mobil di jalan bergelombang dengan baik, maka susunan kerangka pada mobil memiliki massa $=1946 \mathrm{~kg}$ dan gaya gravitasi $=-981.001 \mathrm{~cm} / \mathrm{s}^{2}$

2. Mengetahui hasil gerakan animasi mobil pada jalan bergelombang dengan toleransi jarak antara roda mobil dan lintasan yaitu 4,44 $\mathrm{cm}$ tanpa menerapkan rigid body pada susuna kerangka mobil.

3. Menghasilkan gerakan animasi mobil pada jalan bergelombang dengan hasil baik dimana toleransi jarak antara roda mobil dan lintasan yaitu $0,045 \mathrm{~cm}$ setelah menerapkan rigid body pada susuna kerangka mobil.

\section{Daftar Pustaka}

[1] Yu, Y., Yang, J., Zan, X., Huang, J., \& Zhang, X. (2017). Research of Simulation in Character Animation Based on Physics Engine [Research article]. https://doi.org/10.1155/2017/4815932

[2] Zulnaidi. (2007). Metode Penelitian. Universitas Sumatera Utara. Medan.

[3] Fazeli, N., Tedrake, R., \& Rodriguez, A. (2018). Identifiability Analysis of Planar RigidBody Frictional Contact. In Robotics Research (pp. 665-682). Springer, Cham. https://doi.org/10.1007/978-3-319-60916-4_38

[4] Chatterjee, A., \& Ruina, A. (1998). Two Interpretations of Rigidity in Rigid-Body Collisions. Journal of Applied Mechanics, 65(4), 894-900. https://doi.org/ $10.1115 / 1.2791929$

[5] McHenry, R. R. (2014). The Role of Vehicle Dynamics Simulation in Highway Safety Research. ASME 16th International Conference on Advanced Vehicle Technologies, 1-16.

[6] Aryanto, S. (2018). Implementasi rigid body pada rigging terhadap animasi dinamis model kendaraan tiga dimensi. Angkasa: Jurnal Ilmiah Bidang Teknologi, 10(1), 7788.

[7] Kurniadi, Y., Liliana, L., \& Purba, K. R. (2016). Pembuatan Aplikasi Simulasi Ujian Praktik Pengambilan Surat Izin Mengemudi Kendaraan Roda Empat. Jurnal Infra, 4(2), 110-115. 
[8] Hidayat, D., Istiyanto, J., Sumarsono, D. A., \& Marta, A. (2017). Investigasi Gaya Kontak/Impak Pada Main Landing Gear Pesawat Komuter Dengan Pendekatan MultiBody Simulation (MBS) Rigid Models. Jurnal Teknologi Dirgantara, 15(1), 1-10.

[9] Djuliandri, F. R., Triwiyatno, A., \& Setiyono, B. (2016). Desain Sistem Kontrol Fuzzy Untuk Kendali Sudut Pitch Pada Model Pesawat Konvensional Dengan Tipe Fixed Wing. Transient, 5(2), 343-348.

[10] Syamsuar, S. (2017). Metoda Short Takeoff Landing (Studi Kasus Prestasi Terbang Takeoff-Landing Pesawat Udara Turbo Prop CN235). Warta Ardhia, 41(2), 49-58. 